\section{Climate change and the institutional resilience of international river basins}

\author{
Lucia De Stefano
}

Oregon State University

James Duncan

Oregon State University

Shlomi Dinar

Florida International University

Kerstin Stahl

University of Freiburg

Kenneth M Strzepek

University of Colorado at Boulder

\author{
Aaron T Wolf \\ Oregon State University
}

Journal of Peace Research

49(1) 193-209

(C) The Author(s) 2012

Reprints and permission:

sagepub.co.uk/journalsPermissions.nav DOI: $10.1177 / 0022343311427416$ jpr.sagepub.com

\section{@SAGE}

\begin{abstract}
In the existing 276 international river basins, the increase in water variability projected by most climate change scenarios may present serious challenges to riparian states. This research maps the institutional resilience to water variability in transboundary basins and combines it with both historic and projected variability regimes, with the objective of identifying areas at potential risk of future hydropolitical tension. To do so, it combs existing international treaties for sources of institutional resilience and considers the coefficient of variation of runoff as a measure of past and future water variability. The study finds significant gaps in both the number of people and area covered by institutional stipulations to deal with variability in South America and Asia. At present, high potential risk for hydropolitical tensions associated with water variability is identified in 24 transboundary basins and seems to be concentrated mainly in northern and sub-Saharan Africa. By 2050, areas at greatest potential risk are more spatially dispersed and can be found in 61 international basins, and some of the potentially large impacts of climate change are projected to occur away from those areas currently under scrutiny. Understanding when and where to target capacity-building in transboundary river basins for greater resilience to change is critical. This study represents a step toward facilitating these efforts and informing further qualitative and quantitative research into the relationship between climate change, hydrological variability regimes, and institutional capacity for accommodating variability.
\end{abstract}

\title{
Keywords
}

climate change, freshwater treaties, resilience, river basin organizations, transboundary, water variability 


\section{Introduction}

Transcending political boundaries, river basins shared by two or more countries pose particularly challenging management problems. In transboundary basins, the unifying principles of integrated watershed management clash with the forces of state sovereignty. While the interdependence exemplified by sharing a river may result in interstate conflict and dispute, it could likewise result in cooperation (Elhance, 1999). To date, studies have shed much light on this relationship considering how physi$\mathrm{cal}$, economic, and political factors may affect conflict and cooperation (e.g. Lowi, 1993; Hensel, Mitchell \& Sowers, 2006). In its most extreme form, the water-conflict relationship has been expressed in the water-wars thesis (Starr, 1991). While the great majority of academic studies have criticized this alarmist claim as sensationalist at best (Wolf \& Hamner, 2000), others have challenged these more sobering and optimistic accounts by speculating about the effects of climate change on international water (Working Group II, n.d.).

Overall, climate change is expected to intensify security concerns within or between countries or within river basins (Nordås \& Gleditsch, 2007; Gleick, 1993). According to Barnett (2003: 9), climate change may have indirect negative effects that can undermine the legitimacy of governments, undermine individual and collective economic livelihoods, and affect human health through reduced availability of food and increased exposure to new disease vectors. A report written by a group of retired senior military officers attests that one of the most destabilizing impacts from climate change will be reduced access to freshwater, which could lead to conflict in certain areas (CNA, 2007: 13-16). Pertaining to the phenomenon of water variability, a 2008 Technical Report of the Intergovernmental Panel on Climate Change has claimed that increased precipitation intensity and variability is projected to increase the risks of flooding and drought in many areas, which will affect food stability as well as water infrastructure and practices (Bates et al., 2008: 3-4).

As climatic variability around the world is expected to change, the resilience of social-ecological systems in the face of these shifts could be influenced by the existence and make-up of international institutions. Resilience is described here as the ability of a system to absorb perturbations without altering the fundamental structure, functions, and feedbacks of both its ecological and social components (Adger et al., 2005; Walker et al., 2006). Such 'second-order resources' enhance the abilities of society to deal with environmental change (Ohlsson \&
Turton, 2000). Formal management regimes governing shared river basins, in the form of international water treaties (including specific stipulations such as water allocation, conflict resolution, and variability management) and river basin organizations, can be particularly instrumental in managing or defusing likely disputes among fellow riparians when faced with climatic change and water variability (Drieschova, Giordano $\&$ Fischhendler, 2008). In their assessment of the Ganges Water Treaty, for example, Salman \& Uprety (2002: 177-186) find that the 1996 Ganges River Treaty may have incorporated important stipulations such as water allocation yet ignored others, including water augmentation (or variability management) and flood mitigation. Having little recourse to deal with water variability has contributed to political tensions between India and Bangladesh.

The study presented here aims to increase our understanding of the global distribution of treaties and the institutional mechanisms they contain. This article uses the geographical approach of risk-mapping based on the vulnerability expressed by presence of treaties and river basin organizations, juxtaposed with the respective basin's exposure to hydrological variability. The objective is to identify which basins may be ill-equipped to deal with climatic change and water variability. Our working assumption is that the existence of these treaty stipulations and organizations will enhance resilience specifically in river basins predicted to experience high variability in the future.

With this mapping analysis we are then able to identify specific basins that may merit further study in light of their potential risk of hydropolitical stress. The study shows that institutional coverage is unevenly distributed across continents and across basins. North America, Europe, and Africa have the highest coverage of spatial extent, while South America and Asia have significant gaps in both the number of people and the spatial extent covered. The majority of high potential risk associated with low institutional coverage and present water variability is found in northern and sub-Saharan Africa. Considering future water variability, our study suggests that this high potential risk may also affect other areas of the globe (e.g. in Central Asia or Eastern Europe), many of which are currently not under scrutiny. By identifying these areas at the global scale, we can contribute to efforts aimed at anticipating and addressing future challenges in transboundary water management posed by climate change.

The outline of this article is as follows. We briefly discuss the linkage between climate change, water variability, and stability within international river basins. We then review the institutional sources of resilience to 
climate change, particularly treaties, and the mechanisms they embody, as well as river basin organizations that are described in the literature and are considered in this research. We then provide a brief description of the data and methodology we used to classify and combine vulnerability and exposure to hazard. Next, the results of a risk classification are presented along with basins that merit further study due to their high potential risk levels. We conclude by discussing the main findings of this study and suggest further research.

\section{Climate change, water variability, and stability in international river basins}

Climate change affects precipitation patterns and river runoff, thus increasing the vulnerability of certain regions and communities to changes in water availability and hydrological extremes (Bates et al., 2008). The historical records of many river basin flows suggest that significant variability and changes in mean flows have already been observed (Milly, Dunne \& Vecchia, 2005; Milliman et al., 2008; Dai et al., 2009), and the predicted effects of climate change may render future river flow variability outside the bounds of previously observed runoff events (IPCC, 2007: 31; Milly et al., 2008). The IPCC notes that as drought-affected areas are projected to increase, adverse impacts on multiple sectors (such as agriculture, water supply, energy production, and health) will likewise rise. Increased flood risk will also pose challenges to society pertaining to physical infrastructure and water quality (IPCC, 2007: 49).

In international river basins, these direct and indirect changes may alter current hydropolitical balances and evidence suggests that the likelihood of political tensions is related to the interaction between variability or rates of change within a basin and the institutional capacity to absorb that change (Wolf, Stahl \& Macomber, 2003; Stahl, 2005; Yoffe, Wolf \& Giordano, 2003; Yoffe et al., 2004). Consequently, regions and basins not governed by treaties or water-related institutions and facing current and future variability may be more vulnerable to tension and conflict. In regions that are already governed by treaties, climate change and variability could affect the ability of basin states to meet their water treaty commitments and effectively manage transboundary waters, especially if such treaties are not suited to dealing with variability and new hydrological realities (Ansink \& Ruijs, 2008; Goulden, Conway \& Persechino, 2009). Variability may thus raise serious questions about the adequacy of many existing transboundary arrangements, even in areas that have exemplified cooperation in the past (Cooley et al., 2009: 28). ${ }^{1}$

Given the links between climate change, water variability, conflict, and cooperation in international river basins, the existence of institutions and river basin organizations seems paramount. Beyond the mere existence of these institutions is their make-up and robustness. Such institutional mechanisms may confer additional resilience onto international treaties.

\section{Institutional sources of resilience to climate change}

Recent research has found that while an international water agreement may not necessarily prevent the emergence of country grievances, these grievances usually result in negotiations (or peaceful management) when an agreement already governs the basin (Brochmann \& Hensel, 2009). Institutions such as international water treaties can contribute to transparency, decrease the transaction costs of cooperation, and clarify expectations among the parties, thus stabilizing hydropolitical relations (McCaffrey, 2003: 157).

While a handful of empirical works have studied the general phenomenon of water treaty signature (Espey \& Towfique, 2004; Song \& Whittington, 2004; Tir \& Ackerman, 2009; Dinar, Dinar \& Kurukulasuriya, 2011), less research has examined the institutional components such treaties embody in a global context (Stinnett \& Tir, 2009). The presence (absence) of institutional stipulations may further reflect on the resilience of treaties, given water variability and climatic change (Gleick, 2010). The international relations and hydropolitics literature has shed insight into which mechanisms could possibly enhance treaty resilience and cooperation.

Guided by the availability of global data as to the existence of particular stipulations and buttressed by existing analysis in the literature, we consider the presence of (a) water allocation mechanisms, (b) variability management mechanisms, (c) conflict resolution mechanisms, and (d) river basin organizations. While we have elected to concentrate on only four major stipulations, we recognize that additional stipulations may add to resilience. Side-payments and issue-linkage, for example, may act as a contract enforcing mechanism specifically in asymmetric contexts (LeMarquand, 1977; Bennett, Ragland \& Yolles, 1998; Dinar, 2006). Our underlying

\footnotetext{
${ }^{1}$ However, Dinar et al. (2010) demonstrate that variability can motivate countries to set up new international agreements so as to deal with changes in runoff and precipitation.
} 
assumption is that the existence of these four institutional stipulations provides a valid first approximation at the global scale of the institutional resilience of transboundary basins to present and future climate change-induced water variability. Below we discuss these four major components. While these stipulations are quite distinct, in some cases one single treaty provision can include information on two different stipulations. For example, it is possible that an allocation mechanism also includes specific stipulations for variability management. In that case we will consider the mere presence of an allocation mechanism as one positive feature of the agreement, and the existence of explicit references to flow variability management as another asset of the treaty.

\section{Allocation mechanism}

The presence of allocation mechanisms in agreements pertaining to water quantity and even hydropower may suppose greater certainty in the water sharing among riparian countries (as opposed to allocation uncertainty), which could be preferable in the context of climate uncertainty. Drieschova, Giordano \& Fischhendler (2008), for example, enumerate a variety of stipulations including direct and indirect allocation mechanisms and general principles for allocation. Direct allocation includes stipulations that divide specific water quantities among the protagonists (see, for example, Cooley et al., 2009). Indirect allocations can include such stipulations as consultations or prioritization of uses, while general principles can include stipulations such as equitable utilization or needs-based approaches (Drieschova, Giordano \& Fischhendler, 2008; Wolf \& Hamner, 2000). Many of the above-cited authors seem to agree that in light of climatic change, treaties that exhibit flexibility are likely to be more suitable for dealing with water variability. Nevertheless, the authors all seem to have slightly different definitions of how flexibility may be operationalized in an international treaty.

Drieschova, Giordano \& Fischhendler (2008) suggest that a more flexible water allocation mechanism is one that divides water by percentage (as opposed to fixed amounts). Despite the advantages of this more flexible mechanism, Drieschova, Giordano \& Fishhendler recognize that any direct allocation mechanism is sometimes buttressed with additional indirect mechanisms that also have some built-in flexibility, because they implicitly recognize that water availability may change and therefore establish the process for which allocations will be determined. McCaffrey (2003) argues that flexible allocation mechanisms are those that recognize that water allocations may have to be reduced due to water availability in particular circumstances. Finally, Cooley et al. (2009) emphasize allocations that specify that an upstream riparian deliver a minimum flow to a downstream riparian and, like McCaffrey, praise mechanisms that permit countries in specific situations to make up owed water allocations in a future period when more water is available.

Because treaties may include a range and combination of stipulations that jointly achieve flexibility (in a context of water variability), it is often difficult to assess agreements for their flexibility in a uniform fashion. Moreover, the effectiveness of the particular allocation mechanisms can vary widely due to the influence of local context and hydrological regime, making it difficult to establish a general rule on which specific allocation stipulations are more suitable (relative to others) to deal with water variability. For these reasons, we assume that it is the general presence of allocation stipulations, as opposed to treaties that neglect to codify any allocation division at all, that may contribute to institutional resilience of a basin in light of water variability.

\section{Variability management}

Variability management stipulations are designed to deal with climatic extremes such as droughts and floods or other specific variations. Such extreme events inflict severe damage on the environment and populations resulting in both tangible and intangible effects (Bakker, 2006). Variability thus increases the demand for infrastructure development and the need to manage water demand and supply (Global Water Partnership, 2000). The mere existence of such stipulations implies that the treaty parties not only acknowledge the temporal variability of water availability but may also better prepare basin states to deal with extreme events.

The literature points to a number of specific treaty mechanisms that enhance resilience to drought. Combined with some of the allocation mechanisms discussed above, authors have pointed to immediate consultations between the respective states, stricter irrigation procedures, water allocation adjustments, specific reservoir releases, and data sharing (McCaffrey, 2003; Turton, 2003). Examples of treaties that have stipulated these mechanisms in some form include the 1996 Ganges River Agreement, the 1997 Cuareim River Agreement, the 1970 Lake Lanoux Agreement, and the 1989 Vuoksi River/Lake Saimaa Agreement. ${ }^{2}$

\footnotetext{
2 These treaty examples (and others provided further below) can be located in the International Freshwater Treaties Database of the Transboundary Freshwater Dispute Database (TFDD).
} 
Pertaining to flood issues, the establishment of specific flood-control mechanisms is likewise important. Examples of specific stipulations to mitigate floods include transboundary warning systems, information exchange, the construction of reservoirs and levees, floodwalls, channelization, and the regulation of land use (Rossi, Harmancioğlu \& Yevjevich, 1994). In her study of transboundary flood and institutional capacity, Bakker (2009) finds that, on average, death and displacement tolls were lower in the basins with flood-related institutional capacity (which included flood-related treaty mechanisms).

Based on the above discussion, we expect that treaties that stipulate specific variability management mechanisms (whether they are intended for drought or flood mitigation), as opposed to those that do not stipulate such mechanisms, will bode better for treaty resilience, especially in the context of variability.

\section{Conflict resolution}

Conflict resolution mechanisms, such as third-party involvement or arbitration, could prove invaluable, especially when there are conflicting interpretations of the agreement or when the actions of one country are perceived to negate the agreement's conditions (Global Water Partnership, 2000). Conflict resolution mechanisms also provide a forum for discussing resource and environmental changes not envisioned in the treaty (Drieschova, Giordano \& Fishhendler, 2008). The extent to which a treaty stipulates how disputes are to be resolved among the parties relates to the level of confidence the parties may have that their concerns will be met in a fair and safe environment. The 1992 Agreement between South Africa and Swaziland pertaining to the Maputo and Incomati Basins, for example, stipulates three stages of dispute resolution including direct negotiations between the parties, an arbitral tribune, and a United Nations appointed arbitrator.

As mentioned before, historically, extreme events of conflict over water have been statistically somewhat more frequent in regions characterized by high interannual hydrologic variability. Therefore, the existence of established conflict resolution mechanisms can be crucial for assuaging tensions that may arise during extreme climatic events and in a context of climate uncertainty.

\section{River basin organizations}

Joint commissions, governing councils, directorates, or river basin organizations (which we herein refer to collectively as RBOs) may also contribute to resilience.
According to Chasek, Downie \& Brown (2006) regime effectiveness may be at the heart of the success of treaties and institutions. Effectiveness, according to Haas, Keohane \& Levy (1993), implies that there exists a hospitable contractual environment (among other necessary conditions). This environment, in turn, provides states with the ability to negotiate with reasonable ease, comply with the treaty's tenets without fear that others are cheating or free-riding, monitor each other's behavior, and enforce decisions (see also Susskind, 1994). Depending on their form and function, RBOs can provide such a medium for achieving effectiveness and an appropriate environment for facilitating cooperation (Dombrowsky, 2007).

In addition to being mandated with implementing any treaty obligations and proposing future water plans, projects, and models (Cooley et al., 2009), the $\mathrm{RBO}$ is often entrusted with a monitoring mandate (e.g. 1995 Agreement over the Mekong River). As implied above, monitoring stipulations are particularly important since states often fear that fellow states to an agreement may cheat or free-ride (Keohane \& Martin, 1995). A conflict resolution mandate, while more often delegated to an external agency (see above), is sometimes consigned to the RBO at least as a first phase of dispute settlement (e.g. 1998 Agreement over the Zarumilla River). Enforcement mechanisms, when they are directly present in a given water treaty, are also undertaken by the RBO (e.g. a Governing Council in the case of the 1973 Agreement between Brazil and Uruguay over the Parana River).

In her study of the Indus Basin, for example, Zawahri (2009) finds that the joint commission established has essentially played an invaluable role in the Indus Waters Treaty's implementation since 1960. According to Zawahri, it is in large part due to the overwhelming success of the joint commission to negotiate, monitor, and manage the Indus regime that stable cooperation over water has existed between the two riparians since the treaty's inception. Along the lines of this example, we expect that basins equipped with a transboundary $\mathrm{RBO}$ will deal better with present and projected water variability.

\section{Methods, data, and analysis}

This research followed a sequence of five steps to combine institutional and climate-related information about basin-country units. First, we refined the Transboundary Freshwater Dispute Database (TFDD; Yoffe, Ward \& 
Wolf, 2000) by increasing the spatial resolution from river basin to basin-country unit (BCU) and populating this database with a content analysis of all available transboundary water treaties. We then categorized the vulnerability of each BCU by rating international water treaties according to their potential resilience to hydrological variability (based on the presence of the above stipulations) and by the presence of a RBO. Next, we classified exposure to hydrological variability based on the absolute variability in the past and on the projected relative change in hydrological variability for each BCU. We then classified BCUs by combining maps of hydrological exposure and vulnerability. Using these classifications, we identified basins of significant interest for future study due to their potential risk.

\section{The basin-country unit spatial database}

The TFDD contains tabular and spatial information on 276 transboundary freshwater river basins and more than 400 international, freshwater-related agreements worldwide. Recent work expanded the breadth of the collection, adding 240 agreements to the database, as well as its depth through a content analysis of over 40 dimensions such as enforcement, conflict resolution, nonwater linkages, etc. Previously, all treaty data in the TFDD were linked to basins and countries separately, and part of this research involved shifting to the basincountry unit for analysis. We define the basin-country unit as the spatial portion of a basin that is within a single country, such that, for example, the Chira basin shared between Peru and Ecuador, is analyzed separately as the Chira-Peru BCU and the Chira-Ecuador BCU. This resolution with a clear spatial reference of transboundary agreements allows the identification of gaps in the spatial extent of existing treaties. The combination of 276 transboundary basins and 148 riparian countries yielded 747 BCUs covering a total of 61.962 million $\mathrm{km}^{2}$ of the earth's surface and hosting a total of approximately 2.748 billion people.

To better represent the spatial extent of treaty documents, the concept of the territorial treaty application was introduced and defined as the set of present-day BCUs to which the treaty applies. This allowed water agreements signed by colonial powers or nation-states that no longer exist in their present configuration to be mapped and analyzed consistently. Though the influence or existence of these countries may change in a given place over time, agreements signed by these parties may still influence water management in these areas, as established under the 1969 Vienna Convention on the
Law of Treaties. To determine the territorial treaty application, treaties that referenced non-existent countries were identified and then examined using a variety of data sources on boundary delineations (Anderson, 2003) and the political history of territorial change (Tir et al., 1998).

\section{Treaty and river basin organization capacity}

We considered the capacity of each BCU to deal with current and climate change-driven water variability by recording five components that were then additively combined to give the treaty-RBO score. The first component is the presence of a treaty. Relevant treaties included those with a focus on water as a scarce or consumable resource, a quantity to be managed, or an ecosystem to be improved or maintained (Hamner \& Wolf, 1998). This kept the focus on mechanisms directly related to management of water resources, and resulted in 405 treaties being scored while 283 treaties were excluded. Further scores are given for the presence of water allocation mechanisms, flow variation management provisions, and conflict resolution mechanisms. In addition, a score was given to BCUs that had a river basin organization or joint water management commission present (Table I). While data on the first four components were obtained by using the TFDD database, for the fifth component we consulted a number of sources (official agreements, secondary literature, internet, and contacts with international agencies) to find evidence of the actual existence of RBOs. The final list of RBOs was also cross-checked with the extant literature (e.g. Dombrowsky, 2007; Wirkus \& Boege 2005; and various UNESCO-IHP publications such as Burchi \& Spreij, 2003).

Once these attributes were evaluated, the final step was to add them together for each BCU. One point was given to a $\mathrm{BCU}$ for each treaty and $\mathrm{RBO}$ component present on that $\mathrm{BCU}$, provided the $\mathrm{BCU}$ had at least one treaty present, resulting in a treaty- $\mathrm{RBO}$ score ranging from zero to five. Finally this score was grouped into vulnerability levels for each BCU, with 'low' representing a treaty-RBO score of four or five, 'medium' representing a score of two or three, and 'high' representing a score of zero or one. We quantified vulnerability in this way for each of the 747 BCUs.

\section{Exposure to hydrological variability and future change}

For each BCU, we used the coefficient of variation (CV) in annual runoff as the key hydrologic indicator of interannual variability. CVs for the 1961-90 World 
Table I. Criteria used to evaluate treaties and river basin organizations

\begin{tabular}{lc}
\hline Criterion & Description \\
\hline Presence of a water treaty & A formal agreement between sovereign nation-states substantively referring to \\
& water as a scarce or consumable resource, a quantity to be managed, or an \\
& ecosystem to be improved or maintained (Hamner \& Wolf, 1998). Geo- \\
graphic scope must be specific enough to identify that, at minimum, the & treaty applies to all waters shared between signatories. \\
Mater allocation & $\begin{array}{l}\text { Mechanisms for allocating water for water quantity and/or hydropower uses. } \\
\text { in flow. }\end{array}$ \\
Variability management & $\begin{array}{c}\text { Mechanism(s) specified to address disagreements among the signatories, } \\
\text { including arbitration, diplomatic channels, a commission, third-party } \\
\text { involvement, and/or a permanent judicial organ. }\end{array}$ \\
A bilateral or multilateral body of officials representing participating \\
governments in dialogue about coordinated management of international
\end{tabular}

Meteorological Organization climate normal period (referred to as 'present') and for the time slice 204555 ('2050') were derived for each BCU. The CV data were obtained from the World Bank's Water and Climate Change project (World Bank, 2009). The historic runoff data were simulated with the global hydrologic model CLIVAR driven with historic climate data from 1961 to 1990. The future projections of runoff were derived by driving the same hydrological model with the climate data modified according to the precipitation and temperature changes projected by Global Climate Models that assumed the IPCC AR4 A1B emissions scenario. From the many climate models available, only three models were kept and available to this study. They span all impact levels ('wettest', 'middle', and 'driest') based on the change in a climate moisture index for each World Bank Region.

We created two classifications of hydrological hazard for each BCU, one based on the present variability and one based on a combination with projected change in variability by 2050. Following Vörösmarty et al. (2005), the absolute CVs characterizing the 'present' were grouped into three levels: 'low' $(\mathrm{CV}<0.25)$, 'medium' $(0.25 \leq \mathrm{CV} \leq 0.75)$ and 'high' $(\mathrm{CV}>$ $0.75)$ variability. The relative change in variability was calculated as the percentage change from the present $\mathrm{CV}$. The 'worst case', that is, the largest relative (future) change among the three available models was selected. The future hazard level for a BCU was determined by taking the present variability level and increasing it by a step if the projected increase in variability was greater than $15 \%$. The one exception was when the present hazard level was already high. In that case, the future hazard level would remain high regardless of the level of change in variability. Hazard levels were calculated for only 735 BCUs because modeling constraints prevented historic and future variability regimes from being simulated for 12 small BCUs.

\section{Combining treaty-RBO capacity with variability and variability change}

Following the definition of risk as a combination of exposure to a hazard and vulnerability (e.g. Crichton, 1999), we defined potential risk levels by combining the exposure to hydrological variability (hazard) with the treaty-RBO score (vulnerability). The BCUs with the highest risk are those with the lowest treaty-RBO score (high vulnerability) and the greatest exposure to hydrological variability (high hazard). An application of this model is demonstrated in the online Methodology Codebook.

As a final step, we identified basins that may deserve further study by focusing on those BCUs with the highest present or future risk. To this group, we applied a filter that assessed the relative importance of each BCU to its entire basin in terms of mean annual discharge from the sub-basin, population, irrigation, or area. If a BCU has a significant share of any of these elements, institutional mechanisms to deal with variability appear more relevant than in other BCUs with the same level of potential risk but a small share of the basin. For instance, pressure to improve institutional capacity may be higher in densely populated areas as opposed to scarcely populated areas. Equations and terms used to implement this filtering process can be found in the online Methodology Codebook. 
Table II. Basin-country units with individual treaty-RBO components by continent (\%)

\begin{tabular}{lcccccrr}
\hline & \multicolumn{5}{c}{ Basin continent } & & Global \\
\cline { 2 - 6 } \cline { 3 - 6 } Individual treaty and RBO components & Africa & Asia & Europe & N. America & S. America & Total \\
\hline At least one water treaty & 50 & 40 & 69 & 64 & 32 & 52 \\
Allocation & 25 & 25 & 33 & 42 & 14 & 28 \\
Variability management & 20 & 18 & 34 & 15 & 6 & 21 \\
Conflict resolution & 35 & 25 & 49 & 44 & 15 & 35 \\
At least one RBO & 40 & 19 & 32 & 56 & 22 & 33 \\
Number of BCUs & 204 & 163 & 192 & 95 & 93 & 747 \\
\hline
\end{tabular}

A single treaty can have multiple components, thus the percentages may exceed 100 for each continent. Each BCU may have one or several treaties with any of these mechanisms. Such possible repetitions are not represented.

\section{Results}

\section{Vulnerability: Treaty and river basin organization capacity}

The treaty-RBO scoring analysis of the $747 \mathrm{BCUs}$ yielded a variety of findings. Table II shows the number of BCUs with at least one treaty-RBO component.

Beyond the presence of a water treaty, conflict resolution was the most frequent component while variability management was the least frequent component globally. The distribution of particular mechanisms by continent shows some patterns in overall coverage as well as the presence of specific mechanisms. Europe and North America consistently emerged as having the highest proportions of coverage, while South America and Asia often had many BCUs without a particular mechanism. RBO distributions differed slightly, but showed similar patterns. The global distribution of treaty-RBO scores by $B C U$ is shown in Figure 1. Overall, almost half of the BCUs in the world had a score of zero and those found in Africa and Asia made up half of this group.

Breaking down the distribution of these different scores in terms of the area covered and the population affected in each continent (Figure 2) provided further interesting insights and can be helpful towards an assessment of their implications and importance. For example, the percentages of total BCUs by region shown in Figure 2a revealed that half of all African BCUs and nearly twothirds of all Asian and South American BCUs had treatyRBO scores of zero, and more than $20 \%$ of BCUs in each continent were not covered by high treaty-RBO scores. The distributions of scores differed remarkably when represented using area and population coverage, as shown in Figures $2 b$ and 2c. Nearly all of the population and area in North America are covered by high treaty-RBO scores. Similar compressions of the low treaty-RBO score shares are seen for all continents except for Asia, where about one-third of the continent area has no treaty coverage. Interestingly, nearly one-third of the population in European and South American transboundary basins is covered by treaty-RBO scores of two or less. Furthermore, close to $20 \%$ of Asia's transboundary basin population has no treaty-RBO coverage, indicating concentrations of poor treaty-RBO coverage where many people may be affected.

A number of basins with large disparities among constituent BCUs were found (disparity being defined as the range between the lowest and highest vulnerability of BCUs of a particular basin). The reason for disparity is that not all riparian states may be signatories of a treaty. The detected disparities are an example of the value of using a BCU approach instead of the river basin approach used in most global-scale analyses of transboundary basins. In some cases, a high disparity may be irrelevant, such as when a certain country comprises a small portion of a transboundary basin. In other cases it may reveal that important actors are absent from the institutions managing a transboundary basin. Of the eight basins that had a disparity of five, the GangesBrahmaputra-Meghna and Indus basins are particularly interesting as China is not party to any variabilityrelated treaties and constitutes significant portions of these basins. These two basins together cover 2.768 million $\mathrm{km}^{2}$ and 872.0 million people. Of the nine basins that had a disparity of four, the Congo/Zaire, Danube, Har Us Nur, Niger, Okavango, and Struma basins stand out because of the significant size or population coverage of their high-vulnerability constituent BCUs. These six basins together encompass 253.8 million people and 7.477 million $\mathrm{km}^{2}$. Seven additional basins had a disparity of three for their constituent BCUs, while many basins had disparities of one or two. 


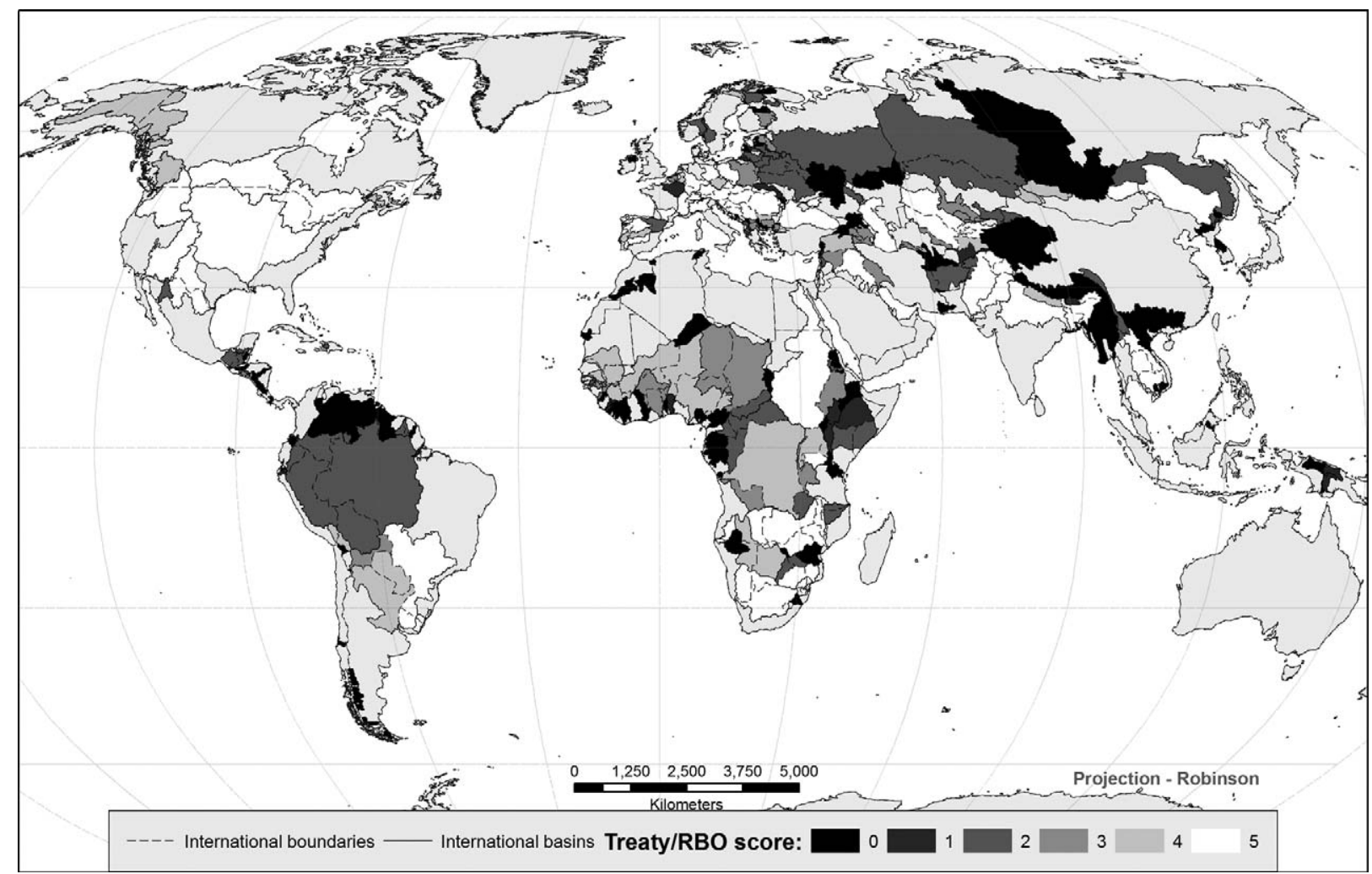

Figure 1. Global distribution of treaty-RBO scores aggregated to each basin-country unit.
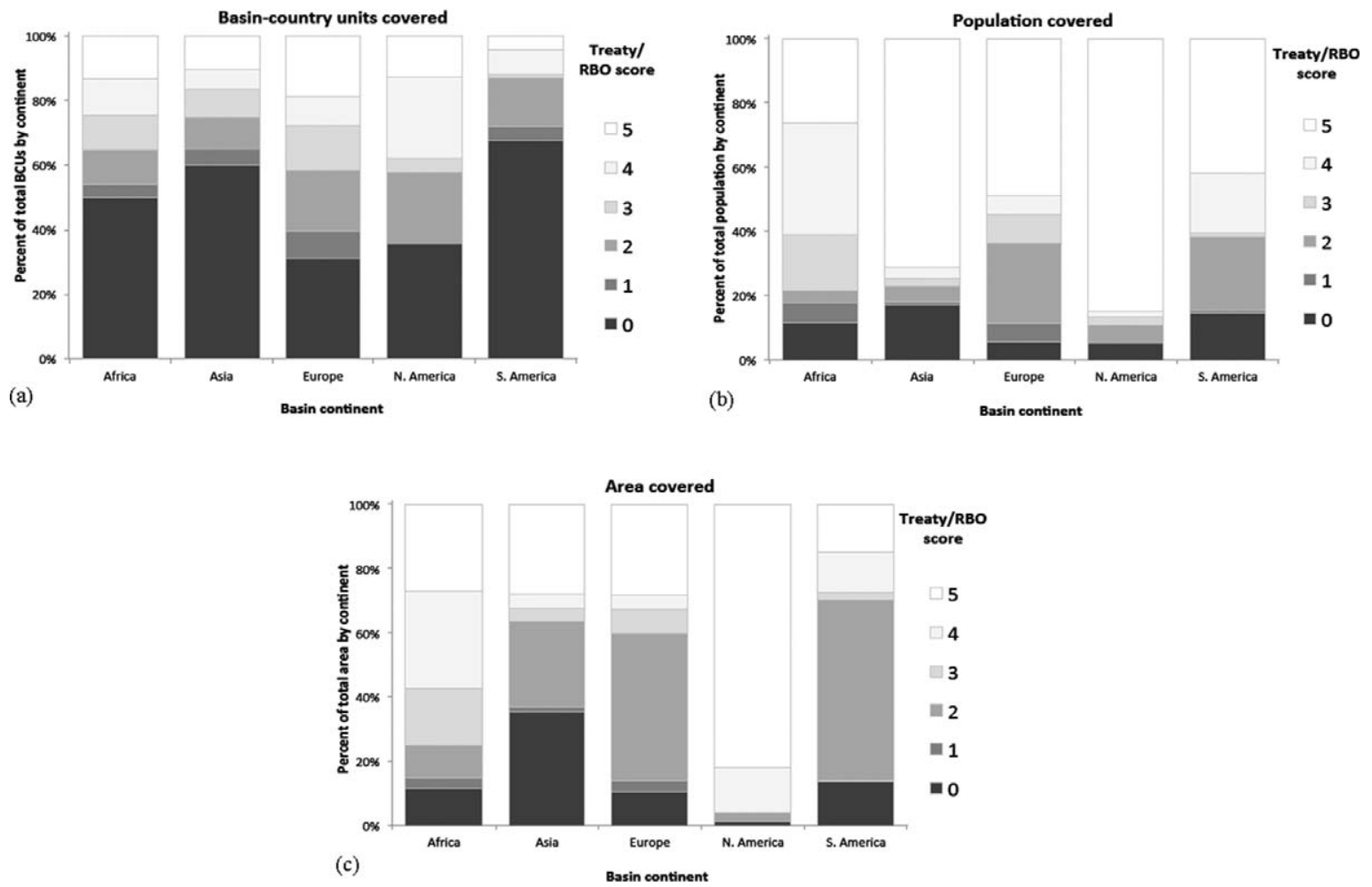

Figure 2. Percentage of coverage by each treaty-RBO score for each continent. 
Hazard: Exposure to hydrologic variability and future change in variability

Figure 3 shows the global distributions of hazard classes for present and future. For present hazard, clear spatial patterns can be identified, with the highest degree of variability generally found in transitional climate zones such as the outer tropics and sub-tropics, while core areas of the polar and tropical climate regions experience low variability. Africa stands out as the continent with the largest share of exposure to high hazard, since it hosts $66 \%$ of all BCUs and $97 \%$ of the population found in this class globally.

The majority of BCUs is predicted to experience increases in runoff variability by 2050 . In total, 110 BCUs increase from medium present hazard to high future hazard. This means that the total share of BCUs in the highest hazard level increases from $8.7 \%$ in the present to $23.4 \%$ by 2050 . The changes by continent are fairly even and Africa still stands out with high hazard levels. In terms of population exposure to hazard, at present, nearly half the world's transboundary population is in the lowest hazard level, but in the future, only $30 \%$ is projected to be in the lowest hazard level, while $62 \%$ will be in the medium hazard level. The share of the world's population found in the highest hazard level increases from presently $3 \%$ to $8 \%$ in the future.

\section{Potential risk: Combining treaty and RBO capacity with exposure to variability}

Table III displays the count of BCUs in each combination of vulnerability and hazard classes. Of particular interest are the cases where a high degree of hazard from exposure to variability is coupled with high vulnerability in the institutional regime (bold entries in Table III). There were 41 BCUs (distributed in 24 international basins that, together, host 332 million people) at high risk under present variability conditions, while 94 BCUs are at high risk when incorporating future variability (encompassing 56 million inhabitants $-2 \%$ of the world's transboundary population - in 61 international basins that, together, cover 415 million inhabitants). Since we did not simulate possible changes in institutional arrangements, changes in risk between the present and 2050 are solely due to climate change-induced shifts in runoff variability.

There were clear spatial concentrations of BCUs at highest risk for the present period. Out of a total of 41 high-risk BCUs, 25 were located in Africa (primarily in northern and sub-Saharan Africa), seven were in Asia (primarily in the Middle East and south-central Asia), and nine were found in South America (primarily small basins along the Andes). Conversely, the lowest-risk BCUs were found primarily in western and central Europe, along the USA-Canada border and in Southeast Asia.

The distribution of potential risk by 2050 shows significant concentrations of BCUs at the highest risk in Africa (46 BCUs). African BCUs with over 1 million people that move to the highest risk class include: Ethiopia's shares of the Awash and Lake Turkana basins, which together account for 31 million people, the Moroccan portion of the Dra $(1.07$ million people), and the Zimbabwean portion of the Sabi (2.89 million people). While for the present period high risk in Asia was concentrated entirely in the Middle East, by 2050 several basins in Central Asia are at high risk, such as the Kura-Araks basin between Georgia and Turkey (3.43 million). Seven European basins, mostly in central and eastern Europe, are in the highest risk level by 2050. Beyond these, many small Central American basins are found to be at high risk in the future, as well as the Catatumbo basin in South America, shared between Columbia and Venezuela (1.26 million people).

The last step of our study identified high-risk units that merit further study: 24 BCUs, distributed in 14 transboundary basins, encompassing $505,000 \mathrm{~km}^{2}$ and 11.91 million people (Table IV). One-third of the basins identified have all constituent BCUs in the highest risk group, indicating that there is a significant risk of basin-wide impacts from climate change.

The picture portrayed by these data is two-fold. First, there are those well-known basins that are currently at high risk, such as the Congo/Zaire, the Niger, and Lake Chad. Secondly, there are basins with a medium present variability that are projected to experience substantial increases in variability, such as the Catatumbo basin shared by Venezuela and Colombia. Some of the BCUs in this latter group have very high population densities, such as the Turkish portion of the Asi/Orontes (101 people $/ \mathrm{km}^{2}$ ), which could exacerbate the human impacts of climate change. It is interesting to note that, with two exceptions, all the basins identified which merit further study due to present variability (eight in total) are in Africa. Conversely, by 2050, only half of the basins identified are in Africa, the rest being distributed between Latin America and Eastern Europe/Western Asia.

\section{Discussion and conclusions}

International water agreements and RBOs are considered important instruments for dealing with changes in 

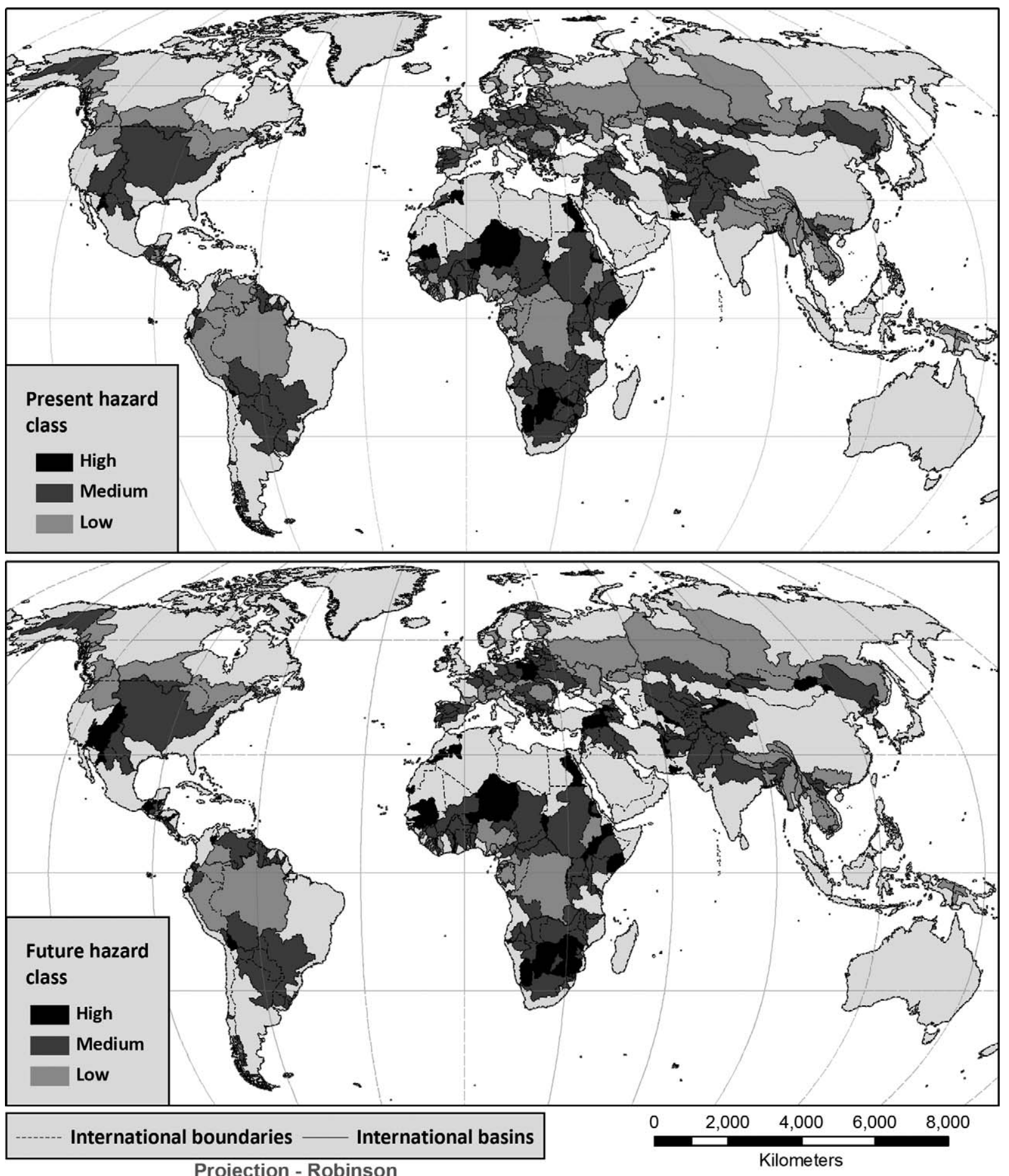

Figure 3. Global distribution of basin-country units in present and future hazard classes.

shared basins. Beyond their mere existence, the make-up and design of treaties, RBOs, and related provisions are anticipated to be particularly important in assuaging potential interstate conflict or country grievances, which may be caused by an increase in interannual water variability due to climate change.
The data analysis revealed marked differences between regions in the frequency of occurrence of certain mechanisms, particularly for allocation and variability mechanisms, and for the presence of RBOs. Gaps in the institutional coverage of population and area of transboundary basins should be further 
Table III. Vulnerability of BCUs and population, present and future hazards

\begin{tabular}{|c|c|c|c|c|c|c|c|}
\hline & \multicolumn{3}{|c|}{ Present hazard level } & \multicolumn{3}{|c|}{ Future hazard level } & \multirow[b]{2}{*}{ Total BCUs } \\
\hline & High & Medium & Low & High & Medium & Low & \\
\hline \multicolumn{8}{|c|}{ Vulnerability level (no. of $B C U_{s}$ ) } \\
\hline High & 41 & 199 & 146 & 94 & 174 & 118 & 386 \\
\hline Medium & 9 & 113 & 51 & 46 & 93 & 34 & 173 \\
\hline Low & 15 & 111 & 50 & 35 & 93 & 48 & 176 \\
\hline Total BCUs & 65 & 423 & 247 & 175 & 360 & 200 & $\begin{array}{c}735 \\
\text { Total population } \\
\quad \text { (in millions) }\end{array}$ \\
\hline \multicolumn{8}{|c|}{ Vulnerability level (\% of population) } \\
\hline High & 0.27 & 7.78 & 7.99 & 2.05 & 6.77 & 7.23 & 441 \\
\hline Medium & 0.38 & 8.51 & 6.29 & 1.92 & 7.75 & 5.51 & 417 \\
\hline Low & 2.37 & 31.55 & 34.86 & 4.25 & 47.07 & 17.46 & 1890 \\
\hline $\begin{array}{l}\text { Total population } \\
\text { (in millions) }\end{array}$ & 83 & 1315 & 1350 & 226 & 1693 & 8309 & 2748 \\
\hline
\end{tabular}

Bold entries are the highest risk categories.

analyzed as they could reveal a potential institutional weakness leading to hydropolitical stress in illequipped transboundary areas. A number of basins had large disparities among constituent BCUs in their treaty and $\mathrm{RBO}$ coverage, demonstrating the value of using a BCU approach and flagging basins where institutional imbalance in the relationships among riparian countries could seriously hamper dialogue and management at the river basin scale.

BCUs in the highest potential risk class under current variability conditions are clearly spatially concentrated in northern and sub-Saharan Africa, pointing to the need to focus on those two regions to assuage possible tensions related to variability. Interestingly, other basins where transboundary disputes are frequent (e.g. Indus, Ganges, Mekong) did not stand out in our analysis for present variability, suggesting that other causes can be behind water-related tensions. BCUs in the highest level of risk due to variability change by 2050 were more spatially dispersed than in the present.

Fourteen basins were identified as particularly interesting for further study based on their high level of potential risk and their relevance in terms of population, area, discharge, and intensity of water use. It is interesting to note that, with two exceptions, all the basins identified which merit further study due to present variability are in Africa, suggesting that improving the transboundary institutional resilience to water variability should be a priority for the involved countries and the international community. In contrast to the present situation, by 2050 only half of the basins identified are in Africa, the rest being distributed between Latin America and Eastern Europe/Western Asia. With all the caveats related to the precision of future runoff projections (see below), this distribution of basins suggests that some of the potentially large impacts of climate change are projected to occur away from those areas currently under scrutiny. Determining where institution-building should be focused using only historic regimes of variability could miss those areas with the greatest need for increased resilience in their institutional systems to absorb or adapt to change in the hydrologic system. Because of this range in our findings, it is critical for the water resources research and policy community to broaden its focus to include also basins traditionally outside the scope of concern to adequately address the human and institutional impacts of climate change. There are additional basins that no doubt would prove interesting and in need of further study, but our study provides a starting point for understanding what constitutes risk both now and in the future, and what might serve to ameliorate that risk.

In order to better understand the implications of our findings, we should mention some caveats based on the data used. The modeled runoff (derived from World Bank, 2009) represents natural conditions and does not take into account river flow as altered by human use and physical infrastructure such as dams. The chosen indicator, the runoff coefficient of variation, did not take into account seasonal variability or extreme events, which may also pose critical challenges to basin riparians. Moreover, BCUs were treated as unconnected units 


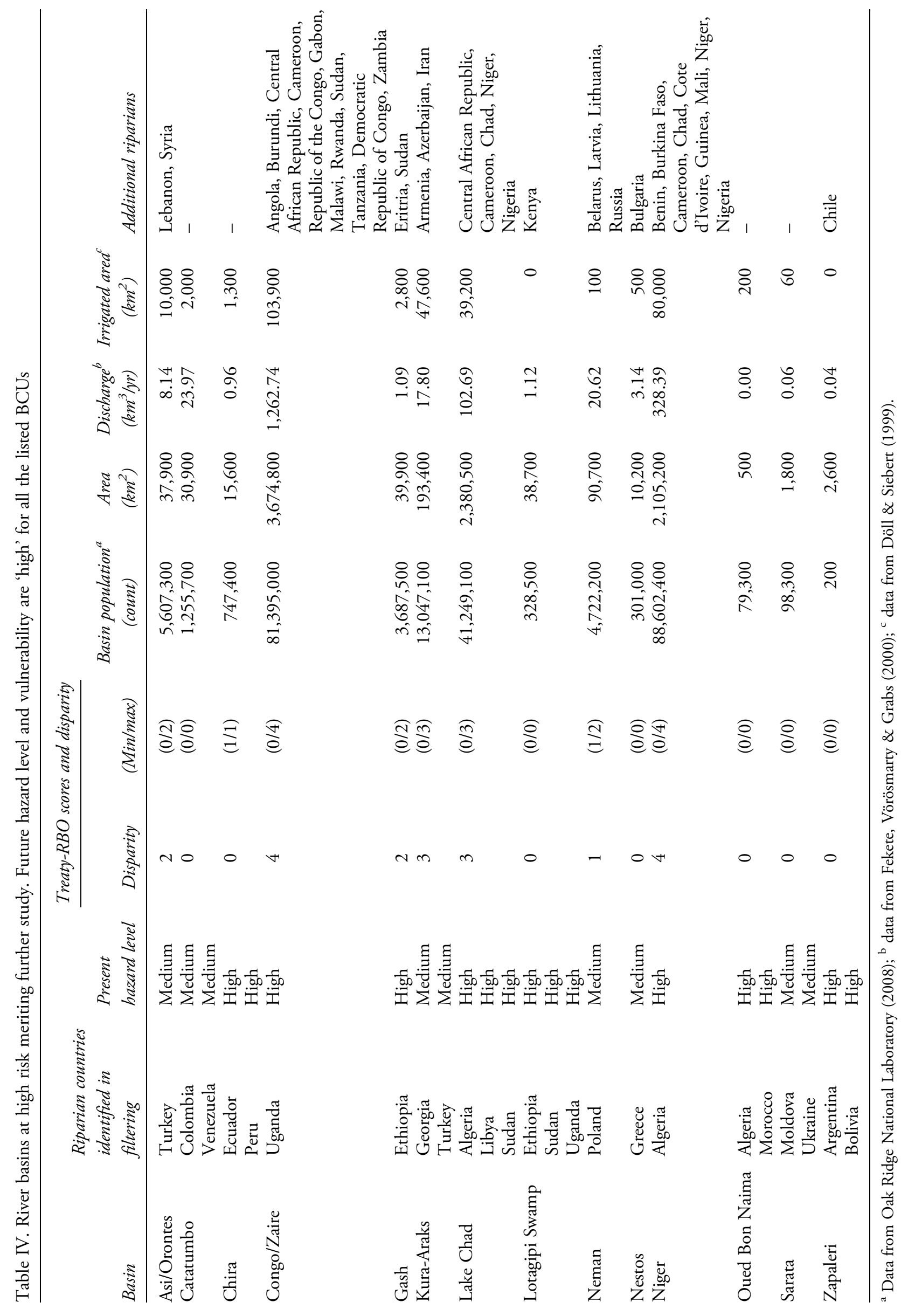


and, consequently, the extent to which high variability changes in one BCU may increase pressure on the water resources of other BCUs in that basin was not considered. In terms of institutional capacity, we argue that water variability may lead to tension and conflict between states and that institutional stipulations and RBOs can potentially assuage such potential tensions. Although we considered and investigated an important array of institutional stipulations, we recognize that other stipulations exist such as non-water linkages, which likewise deserve scrutiny. Additionally, the textual analysis of the treaties limited our analysis to a binary absence/presence of stipulations rather than considering their overall quality. Similarly, the level of treaty implementation and treaty equity need to be included in future research. We assumed that the treaty and river basin organization landscape would not change over time, which may not necessarily be the case. Nonetheless, this assumption allowed us to explore what the existing institutional arena today would look like projected into a future affected by climate change. While this analysis did not empirically and quantitatively estimate or measure how particular contextual factors may directly affect the relationship between treaty-RBO capacity and resilience to variability, it does provide motivation for such future work. Future large-N investigations can thus utilize the rich hydropolitics literature that has considered factors such as militarized interaction, power disparities, regime type, level of interdependence, and geography (Gleditsch et al., 2006; Lowi, 1993; Brochmann \& Hensel, 2009; Toset, Gleditsch \& Hegre, 2000). Further work can also be done on individual basins or regions (as has already been accomplished in varying capacities by Goulden, Conway \& Persechino, 2009; Conway, 2005; Fischhendler, 2004).

In conclusion, this study highlights that the global distribution of treaties and river basin organizations is quite varied and reflects a long and complex history of development in response to specific demands on water systems and larger sociopolitical processes. Likewise, the variability in basin-wide hydrological regimes is unevenly distributed in space and intersects with human use and management in both intranational and international settings. Global climate change adds another layer to this already complex picture. Understanding when and where to target capacity-building for greater resilience to change is critical. This study represents a step toward facilitating these efforts with the goal of motivating further qualitative and quantitative research into the relationship between hydrological variability regimes and institutional capacity for accommodating variability.

\section{Replication data}

The dataset, codebook, and do-files for the empirical analysis in this article can be found at http:// www.prio.no/jpr/datasets.

\section{Acknowledgments}

The study was made possible thanks to a number of colleagues: first and foremost, Ariel Dinar, Vahid Alavian, and Michael Jacobsen, our project manager at the World Bank, who were all instrumental in crafting the framework of the analysis. Andrea Gerlak, Susanne Schmeier, and Marloes Bakker generously contributed to the river basin organization dataset and Itay Fischhendler helped with the structure. The OSU treaty database was vastly improved thanks to close collaboration with the International Water Management Institute; we are grateful to Mark Giordano and his colleagues Alena Drieschova and Jonathan Lautze for their efforts, as we are to Shlomi Dinar for contributing his collection as well. OSU and guest students contributed time and energy: Stephanie Ogden, Yoshiko Sano, Amy McNally, Olivia Odom, Patrick MacQuarrie, Carolyn Jackson, Jehan Jabareen, and Geoff King. We are grateful to Kendra Hatcher, manager of TFDD, and to Lynette de Silva, director of the OSU Program in Water Conflict Management for keeping us all on track. We also thank Nils Petter Gleditsch and two anonymous reviewers for their thoughtful comments on the manuscript.

\section{Funding}

This research was funded by two World Bank-managed trust funds, the Bank-Netherlands Water Partnership Program (BNWPP) and the Water Partnership Program (WPP), for which we are extremely grateful.

\section{References}

Adger, W Neil; Terry P Hughes, Carl Folke, Stephen R Carpenter \& Johan Rockström (2005) Social-ecological resilience to coastal disasters. Science 309(5737): 1036-1039.

Anderson, Ewan W (2003) International Boundaries: A Geopolitical Atlas. New York: Routledge.

Ansink, Erik \& Arjan Ruijs (2008) Climate change and the stability of water allocation agreements. Environmental and Resource Economics 41(2): 133-287.

Bakker, Marloes (2006) Transboundary river floods: Vulnerability of continents, international river basins, and 
countries. Unpublished PhD dissertation, Department of Geosciences, Oregon State University.

Bakker, Marloes (2009) Transboundary river floods and institutional capacity. Journal of the American Water Resources Association 45(3): 553-566.

Barnett, Jon (2003) Security and climate change. Global Environmental Change 13(1): 7-17.

Bates, Bryson; Zbigniew Kundzewicz, Shaohong Wu \& Jean Palutikof, eds (2008) Climate Change and Water. Technical Paper (6). Geneva: Intergovernmental Panel on Climate Change.

Bennett, Lynne; Shannon Ragland \& Peter Yolles (1998) Facilitating international agreements through an interconnected game approach: The case of river basins. In: Richard Just \& Sinaia Netanyahu (eds) Conflict and Cooperation on Transboundary Water Resources. Boston, MA: Kluwer Academic, 61-85.

Brochmann, Marit \& Paul R Hensel (2009) Peaceful management of international river claims. International Negotiation 14(2): 393-418.

Burchi, Stefano \& Melvin Spreij (2003) Institutions for International Freshwater Management, UNESCO-IHP, Technical Documents in Hydrology (3). Paris: UNESCO.

Chasek, Pamela; David Downie \& Janet Brown (2006) Global Environmental Politics, 4th edn. Boulder, CO: Westview.

CNA (2007) National Security and Threat of Climate Change. Alexandria, VA: CNA.

Cooley, Heather; Juliet Christian-Smith, Peter H Gleick, Lucy Allen \& Michael Cohen (2009) Understanding and Reducing the Risks of Climate Change for Transboundary Waters. Oakland, CA: Pacific Institute.

Crichton, David (1999) The risk triangle. In: Jon Ingleton (ed.) Natural Disaster Management. London: Tudor Rose, 102-103.

Conway, Declan (2005) From headwater tributaries to international river: Observing and adapting to climate variability and change in the Nile Basin. Global Environmental Change 15(2): 99-114.

Dai, Aiguo; Taotao Qian, Kevin E Trenberth \& John D Milliman (2009) Changes in continental freshwater discharge from 1948 to 2004. Journal of Climate 22(10): 2773-2791.

Dinar, Ariel; Brian Blankespoor, Shlomi Dinar \& Pradeep Kurukulasuriya (2010) Does precipitation and runoff variability affect treaty cooperation between states sharing international bilateral rivers? Ecological Economics 69(12): 2568-2681.

Dinar, Shlomi (2006) Assessing side-payment and cost-sharing patterns: The geographic and economic connection. Political Geography 25(4): 412-437.

Dinar, Shlomi; Ariel Dinar \& Pradeep Kurukulasuriya (2011) Scarcity and cooperation along international rivers: An empirical assessment of bilateral treaties. International Studies Quarterly 55(3): 809-833.

Döll, Petra \& Stefan Siebert (1999) A Digital Global Map of Irrigated Areas. Kassel World Water Series (1). Center for
Environmental Systems Research, University of Kassel (http://wwdrii.sr.unh.edu/download.html).

Dombrowsky, Ines (2007) Conflict, Cooperation and Institutions in International Water Management: An Economic Analysis. Cheltenham: Elgar.

Drieschova, Alena; Mark Giordano \& Itay Fischhendler (2008) Governance mechanisms to address flow variability in water treaties. Global Environmental Change 18(2): 285-295.

Elhance, Arun (1999) Hydropolitics in the Third World: Conflict and Cooperation in International River Basins. Washington, DC: United States Institute of Peace Press.

Espey, Molly \& Basman Towfique (2004) International bilateral water treaty formation. Water Resources Research 40(April): W05S05.

Fekete, Balázs; Charles Vörösmarty \& Wolfgang Grabs (2000) UNH/GRDC Composite Runoff Fields V 1.0. (http:// www.grdc.sr.unh.edu).

Fischhendler, Itay (2004) Legal and institutional adaptation to climate uncertainty: A study of international rivers. Water Policy 6(4): 281-302.

Gleditsch, Nils Petter; Kathryn Furlong, Håvard Hegre, Bethany Lacina \& Taylor Owen (2006) Conflicts over shared rivers: Resource scarcity or fuzzy boundaries? Political Geography 25(4): 361-382.

Gleick, Peter H (1993) Effects of climate change on shared fresh water resources. In: Irving M Mintzer (ed.) Confronting Climate Change: Risks, Implication Responses. Cambridge: Cambridge University Press, 127-140.

Gleick, Peter H (2010) Water, climate change, and international security. Circle of Blue Water News (http://www.circleofblue. org/waternews/2010/world/peter-gleick-water-climate-changeand-international-security/).

Global Water Partnership Technical Advisory Committee (2000) Integrated Water Resources Management. Stockholm: Global Water Partnership Technical Advisory Committee.

Goulden, Marisa; Declan Conway \& Aurelie Persechino (2009) Adaptation to climate change in international river basins in Africa: A review. Hydrological Sciences Journal 54(4): 805-828.

Haas, Peter; Robert Keohane \& Marc Levy (1993) Institutions for the Earth: Sources of Effective International Environmental Protection. Cambridge, MA: MIT Press.

Hamner, Jesse \& Aaron Wolf (1998) Patterns in international water resource treaties: The Transboundary Freshwater Dispute Database. Colorado Journal of International Environmental Law and Policy 1997 Yearbook: 157-177.

Hensel, Paul; Sara Mitchell \& Thomas Sowers (2006) Conflict management of riparian disputes. Political Geography 25(4): 383-411.

IPCC (2007) Fourth Assessment Report, Climate Change 2007: Synthesis Report, Summary for Policy Makers. Geneva: Intergovernmental Panel on Climate Change. 
Keohane, Robert O \& Lisa L Martin (1995) The promise of institutionalist theory. International Security 20(1): 39-51.

LeMarquand, David (1977) International Rivers: The Politics of Cooperation. Vancouver: Westwater Research Center.

Lowi, Miriam R (1993) Water and Power: The Politics of a Scarce Resource in the Jordan River Basin. Cambridge: Cambridge University Press.

McCaffrey, Stephen (2003) The need for flexibility in freshwater treaty regimes. Natural Resources Forum 27(2): 156-162.

Milliman, John; Katie Farnsworth, Philip Jones, Kevin Xu \& Laurence Smith (2008) Climatic and anthropogenic factors affecting river discharge to the global ocean, 1951-2000. Global Planetary Change 62(3-4): 187-194.

Milly, Paul CD; Krista Dunne \& Aldo Vecchia (2005) Global pattern of trends in streamflow and water availability in a changing climate. Nature 438(9066): 347-350.

Milly, Paul CD; Julio Betancourt, Malin Falkenmark, Robert M Hirsch, Zbigniew W Kundzewicz, Dennis P Lettenmaier \& Ronald J Stouffer (2008) Stationarity is dead: Whither water management? Science 319(5863): 573-574.

Nordås, Ragnhild \& Nils Petter Gleditsch (2007) Climate change and conflict. Political Geography 26(6): 627-638.

Oak Ridge National Laboratory (2008) LANDSCAN 2007 Global Population Dataset (http://www.ornl.gov/sci/landscan).

Ohlsson, Leif \& Anthony Turton (2000) The turning of a screw: Social resource scarcity as a bottle-neck in adaptation to water scarcity. Stockholm Water Front (1): 10-11.

Rossi, Giuseppe; Nilgun Harmancioğlu \& Vujica Yevjevich (1994) Coping with Floods. Dordrecht: Kluwer Academic.

Salman, Salman \& Kishor Uprety (2002) Conflict and Cooperation on South Asia's International Rivers: A Legal Perspective. Washington, DC: World Bank.

Song, Jennifer \& Dale Whittington (2004) Why have some countries on international rivers been successful negotiating treaties? A global perspective. Water Resources Research 40(May): W05S06.

Stahl, Kerstin (2005) Influence of hydroclimatology and socio-economic conditions on water-related international relations. Water International 30(3): 270-282.

Starr, Joyce (1991) Water wars. Foreign Policy (82): 17-36.

Stinnett, Doug \& Jaroslav Tir (2009) The institutionalization of river treaties. International Negotiation 14: 229-251.

Susskind, Lawrence (1994) Environmental Diplomacy: Negotiating More Effective Global Agreements. New York: Oxford University Press.

Tir, Jaroslav \& John T Ackerman (2009) Politics of formalized river cooperation. Journal of Peace Research 46(5): 623-640.

Tir, Jaroslav; Philip Schafer, Paul F Diehl \& Gary Goertz (1998) Territorial changes, 1816-1996: Procedures and data. Conflict Management and Peace Science 16(1): 89-97.

Toset, Hans Petter Wollebæk; Nils Petter Gleditsch \& Håvard Hegre (2000) Shared rivers and interstate conflict. Political Geography 19(8): 971-996.
Transboundary Freshwater Dispute Database (TFDD), International Freshwater Treaty Database, Oregon State University (http://www.transboundarywaters.orst.edu/database/ interfreshtreatdata.html).

Turton, Anthony (2003) A Southern African perspective on transboundary water resources management. Environmental Change and Security Project Report 9: 75-87.

Vörösmarty, Charles J; Ellen M Douglas, Pamela A Green \& Carmen Revenga (2005) Geospatial indicators of emerging water stress: An application to Africa. Ambio 34(3): 230-236.

Walker, Brian; Lance H Gunderson, Ann P Kinzig, Charles Folke, Stephen R Carpenter \& Lisen Schultz (2006) A handful of heuristics and some propositions for understanding resilience in social-ecological systems. Ecology and Society 11(1): 13.

Wirkus, Lars \& Volker Boege (2005) Afrikas internationale Fluesse und Seen. Stand und Erfahrungen im grenzüberschreitenden Gewässermanagement in Afrika an ausgewählten Beispielen [African international rivers and lakes: State and experiences in transboundary management in Africa. Selected examples]. DIE Discussion Paper (7). Bonn: German Development Institute.

Wolf, Aaron \& Jesse Hamner (2000) Trends in transboundary water disputes and dispute resolution. In: Green Cross International (ed.) Water for Peace in the Middle East and Southern Africa. Geneva: Green Cross International, 55-66.

Wolf, Aaron T; Kerstin Stahl \& Marcia F Macomber (2003) Conflict and cooperation within international river basins: The importance of institutional capacity. Water Resources Update 125(June): 31-40.

Working Group II of the Navigating Peace Initiative (n.d.) Water conflict and cooperation: Looking over the horizon. Environmental Change and Security Program (http://www. wilsoncenter.org/index.cfm? topic_id $=1413 \&$ fuseaction $=$ to pics.item\&news_id=22578).

World Bank (2009) Water and Climate Change: Understanding the Risks and Making Climate-Smart Investment Decisions. Water Anchor, Energy, Transport and Water Department. Washington, DC: World Bank.

Yoffe, Shira; Brian Ward \& Aaron Wolf (2000) The Transboundary Freshwater Dispute Database Project: Tools and Data for Evaluating International Water Conflict (http://www.transboundarywaters.orst.edu/publications/).

Yoffe, Shira; Aaron T Wolf \& Mark Giordano (2003) Conflict and cooperation over international freshwater resources: Indicators of basins at risk. Journal of the American Water Resources Association 39(5): 1109-1126.

Yoffe, Shira; Greg Fiske, Mark Giordano, Meredith A Giordano, Kelli Larson, Kerstin Stahl \& Aaron T Wolf (2004) Geography of international water conflict and cooperation: Data sets and applications. Water Resources Research 40(May): W05S04. 
Zawahri, Neda A (2009) Third party mediation of international river disputes: The case of the Indus Basin. International Negotiation 14(2): 281-310.

LUCIA DE STEFANO, b. 1971, PhD in Geological Sciences (Complutense University of Madrid, 2005); postdoctoral research assistant, Oregon State University (2008-09); lecturer, Complutense University of Madrid and research fellow, Water Observatory, Botín Foundation; current main interests: water policy assessment systems, institutional resilience to water scarcity and drought, water conflict management.

JAMES DUNCAN, b. 1981, MS in Geography (Oregon State University, 2010); graduate research assistant, Oregon State University (2009-10); consultant, World Bank; current main interests: landscape ecology, land use change, governance of natural resource management, socialecological resilience.

SHLOMI DINAR, b. 1975, PhD in International Relations (Johns Hopkins University, School of Advanced International Studies, 2009); Associate Professor, Department of Politics and International Relations, Florida
International University; current main interests: environment and security, hydropolitics, international environmental politics, conflict and cooperation over natural resources.

KERSTIN STAHL, b. 1971, PhD in Hydrology (University of Freiburg, 2001); Senior Scientist, Institute of Hydrology, Freiburg; current main interests: climate change impacts on regional hydrology, mountain hydrology, low flow and drought, hydroclimatic variability and change as a challenge in transboundary rivers.

KENNETH M STRZEPEK, b. 1954, PhD in Water Resources Systems Analysis (Massachusetts Institute of Technology, 2001); Professor, University of Colorado at Boulder; current main interests: climate change modeling.

AARON T WOLF, b. 1960, PhD in Environmental Policy Analysis (University of Wisconsin, 1992); Professor, Oregon State University; current main interests: transboundary water conflicts and conflict resolution, environmental policy analysis. 